\title{
Evaluation on Indoor Air Quality Using a Modified Contribution Ratio of Pollution Source
}

\author{
Janghoo Seo* \\ School of Architecture \\ Kookmin University \\ Seoul, South Korea \\ *Corresponding author
}

\author{
Sunwoo Lee \\ Graduate student \\ Seoul National University \\ Seoul, South Korea
}

\author{
Seonghyun Park \\ Graduate student \\ The University of Tokyo \\ Tokyo, Japan
}

\begin{abstract}
Many studies using computational fluid dynamics (CFD) analysis have been performed on the concentration distribution of indoor contaminants generated in building materials. This study was an attempt to quantitatively evaluate the effect of the contaminant emission source on the concentration and breathing quantity in a human breathing area using the contribution ratio of pollution (CRP) along with CFD analysis. The modeled human body is placed lying and sitting in a room. It is ventilated with natural infiltration. We applied these concepts to the more realistic case of inhalation by a human occupant in a room with three dimensional CFD, assuming the human mouth at inhalation to be an exhaust opening. As a result, the contaminant that was emitted from the floor had a significant influence on the breathing quantity of the contaminant. CFD analysis also indicate that the quality of the breathing air depends on the flow field around a human body.
\end{abstract}

Keywords-sorptive building materials; computational fluid dynamics; toluene; simulation

\section{INTRODUCTION}

There have been increasing efforts to improve energy savings and the efficiency of building insulation in industrial structures through the use of new composite chemical building materials. In particular, in the case of high-rise office buildings, which are totally dependent on mechanical ventilation, the deteriorating indoor air quality can have a deleterious effect on the health and work efficiency of the buildings' occupants. [13] In this study, we quantitatively evaluated the effect of the contaminant emission source on the concentration and breathing quantity in a human breathing area using the contribution ratio of pollution source (CRP) index. [4-7]

\section{METHOD}

\section{A. Contribution Factor Assessment using the CRP Index}

CPR $1 *$ is a non-dimensional coefficient that is calculated by dividing the contaminant concentration in the human breathing area by the contaminant concentration at a random location, which is 1.0 at the human breathing area. Therefore, assuming that the surface concentration in each contaminant emission source is the same, if the variation of the CRP1* value near the human breathing area is large, the effect of the indoor environment factor on contaminant diffusion, which occurs in the emission source, is large. CRP $1 *$ is defined by the following equation.

$$
C R P 1 *(x, p)=C_{p} /\left|C_{x}\right|
$$

where $C_{p}$ is the contaminant concentration in the human breathing area $\left(\mathrm{g} / \mathrm{m}^{3}\right)$, and $C_{x}$ represents the mean contaminant concentration at a position $\mathrm{x}\left(\mathrm{g} / \mathrm{m}^{3}\right)$.

CRP1* is an index that represents the concentration distribution in the studied space of the contaminant occurring at each contaminant source, while CRP2 is an index that represents how many rates the contaminant occurring at each source contributes to the contaminant total breathing quantity of humans. Therefore, the sum of the contribution rates of all the contaminant emission sources shall be $100 \%$. CRP2 is defined by the following equation.

$$
C R P 2=H_{p, n} / \sum H_{p}
$$

where $H_{p, n}$ is the contaminant amount taken in by a human $\mathrm{p}$ due to the emission source $\mathrm{n}(\mathrm{g} / \mathrm{h})$, and $H_{p}$ is the total sum of the contaminant amount taken in by a human $\mathrm{p}$ due to the emission source $\mathrm{n}(\mathrm{g} / \mathrm{h})$.

\section{B. CFD Analysis Boundary Condition}

Figure 1 shows the analysis of the target space as per CFD. The length, width, and height of the office space were 8,6 , and $3 \mathrm{~m}$, respectively. The room has two air inlets and two outlets, both of which are in the ceiling and have the same size of $0.4 \mathrm{~m}$ $\times 0.6 \mathrm{~m}$. Fresh air are supplied only by the mechanical ventilation through the inlets; the air flows out of the room through the outlets. A window is installed on the inner wall of the room and is closed. Four humans are present in the target space. Table 1 shows the CFD analysis boundary condition for analysis of the contribution rate of the contaminant emission 


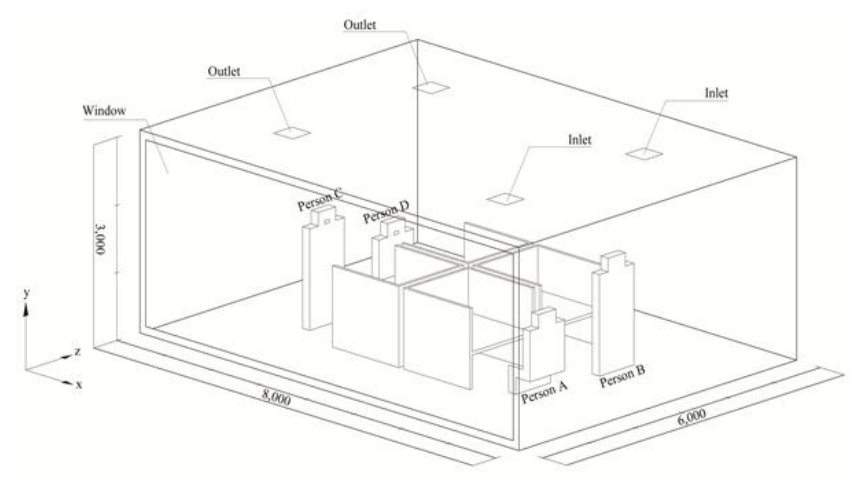

FIGURE I. CFD ANALYSIS MODEL

source. The number of ventilations was 4.0 times/h, which was deemed to be appropriate ventilation, while the temperature of the indoor space was set as $26{ }^{\circ} \mathrm{C}$ to represent summer. The studied contaminant toluene was assumed to diffuse in all directions in the indoor space except for the window glass, where contaminant sorption cannot occur, and the concentration of toluene was set as $182 \mathrm{~g} / \mathrm{m}^{3}$, which is saturation concentration at $26{ }^{\circ} \mathrm{C}$. Furthermore, heat radiation due to the temperature difference between indoors and outdoors and human body heat was taken into consideration. [8-10]

\section{RESULT}

Figure 2 shows that the concentration of the breathing area of each person, which was produced based on the CFD interpretation result, was set to a reference value of 1 , and the concentration distribution of the contaminant was diagrammed using the CPR1 index. Regardless of one's location, if a person was located near the inlet in the same cross-section area, the CPR1 recorded was relatively higher. This was because toluene,

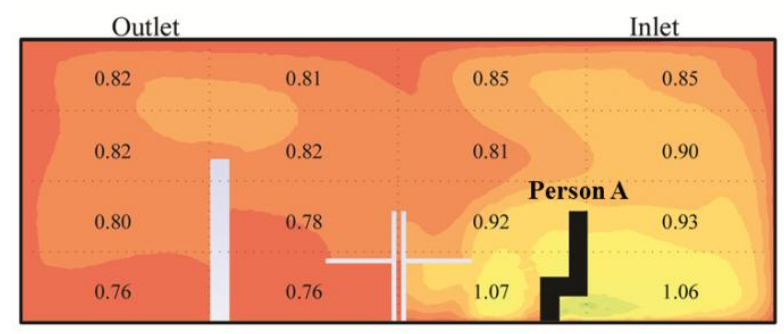

(A) Person A (Plane XY, Z=2150)

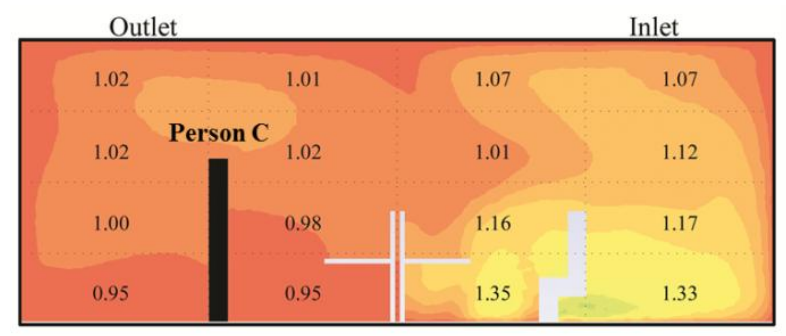

(C) Person C (Plane XY, Z=3850)
TABLE I. CONDITIONS FOR CFD ANALYSIS

\begin{tabular}{|c|c|}
\hline $\begin{array}{l}\text { Turbulent Flow } \\
\text { Model }\end{array}$ & $\begin{array}{l}\text { Low Reynolds Number k- } \varepsilon \text { Model } \\
\text { (Abe-Nagano model) }\end{array}$ \\
\hline $\begin{array}{c}\text { Number of } \\
\text { Meshes }\end{array}$ & 700,000 \\
\hline Inflow Boundary & $\begin{array}{c}U_{y, i n}=2.47 \times 10^{-1}, U_{x, i n}=U_{z, i n}=0 \mathrm{~m} / \mathrm{s} \\
k_{i n}=3 / 2 \cdot\left(U_{y, i n} \times 0.05\right)^{2}, \varepsilon_{i n}=C_{u} \cdot k_{i n}^{(3 / 2)} / L_{i n}, \\
L_{i n}=(1 / 7) L_{o}, L_{o}=0.4 \mathrm{~m}\end{array}$ \\
\hline $\begin{array}{l}\text { Outflow } \\
\text { Boundary }\end{array}$ & $\begin{array}{c}U_{\text {out }}=\text { outflow (mass flow conservation) } \\
k_{\text {out }}, \varepsilon_{\text {out }}=\text { free flow }\end{array}$ \\
\hline Wall Boundary & No-slip \\
\hline Breath Boundary & 14.4 L/min (human standard) \\
\hline Flux Boundary & $\begin{array}{c}H_{\text {human }}=20 \mathrm{~W} / \mathrm{m}^{2}, H_{\text {window }}=K_{\text {window }} \cdot\left(\theta_{R^{-}} \theta_{o}\right) \\
\theta_{R}=305.15 \mathrm{~K}, \theta_{o}=299.15 \mathrm{~K}, K_{\text {window }}=6.39 \mathrm{~W} / \mathrm{m}^{2}\end{array}$ \\
\hline $\begin{array}{c}\text { Analysis of } \\
\text { Diffusion Field }\end{array}$ & $\begin{array}{l}\text { After airflow field analysis, the water (distilled } \\
\text { water) saturation concentration on the surface of the } \\
\text { building material was set to } C_{s}=182 \mathrm{~g} / \mathrm{m}^{3} \text { to analyze } \\
\text { the pollutant diffusion in the space. }\end{array}$ \\
\hline
\end{tabular}

which was emitted from the bottom where the contaminant emission areas were the largest, was diluted by fresh external air supplied through the inlet. On the other hand, in the case of the outlet area where the airflow speed distribution was relatively lower, CRP1* was similar. However, CRP1* is a relative value of the concentration of the contaminant in each location with regard to the concentration of the target person's breathing area. Therefore, its value was also relative, thus it cannot be accepted as a reference value of the assessment. When a person stayed in an area where the variance was lower according to the CRP1* variance near the person, the

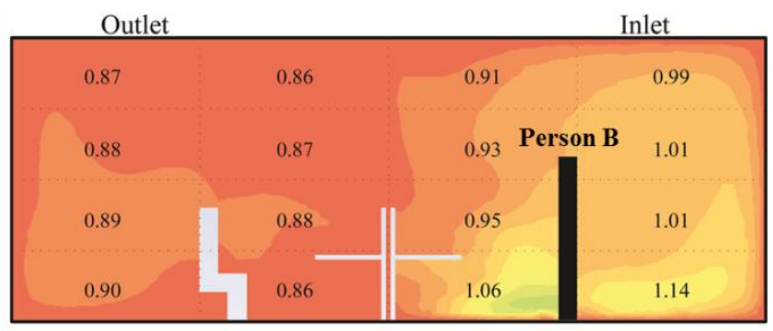

(B) Person B (Plane XY, Z=2150)

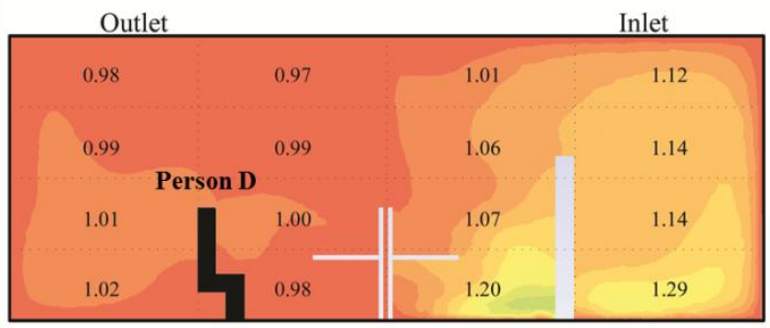

(D) PERson D (Plane XY, Z=3850)

FIGURE II. CFD ANALYSIS RESULTS; CRP1* 

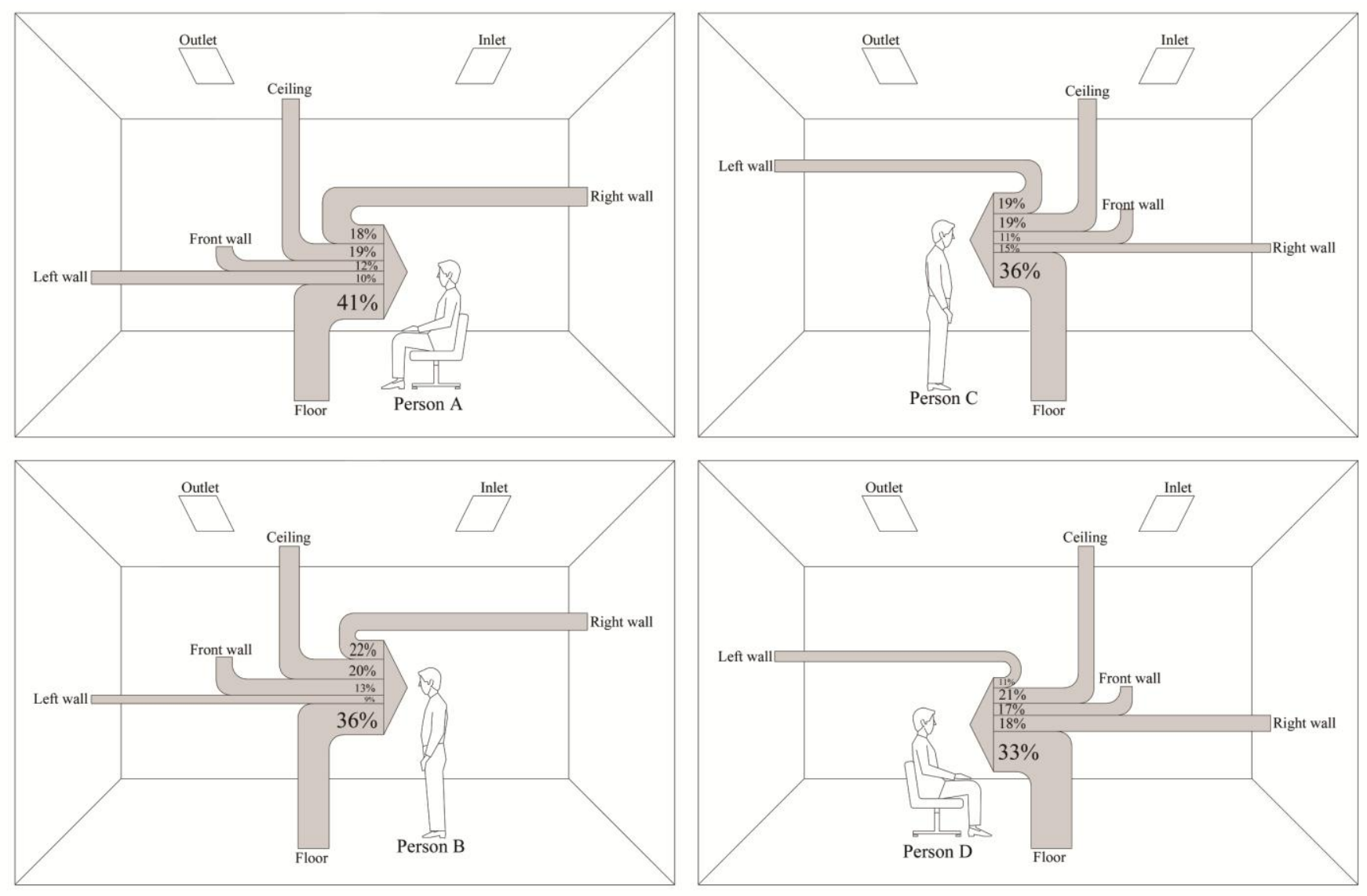

FIGURE III. DISTRIBUTION OF CRP2

TABLE II.

CRP2 FOR PERSON A D

\begin{tabular}{|c|c|c|c|c|c|}
\hline \multirow{2}{*}{ Person } & \multicolumn{5}{|c|}{ Sources of pollutants } \\
\cline { 2 - 6 } & Floor & Ceiling & Right wall & Left wall & Front wall \\
\hline Person A & $41.3 \%$ & $19.6 \%$ & $17.7 \%$ & $9.6 \%$ & $11.7 \%$ \\
\hline Person B & $36.4 \%$ & $19.7 \%$ & $22 \%$ & $9.2 \%$ & $12.7 \%$ \\
\hline Person C & $36.1 \%$ & $18.9 \%$ & $14.8 \%$ & $18.8 \%$ & $11.3 \%$ \\
\hline Person D & $32.6 \%$ & $21.4 \%$ & $18.1 \%$ & $11.1 \%$ & $16.8 \%$ \\
\hline
\end{tabular}

contaminant generated from the adjacent building materials could directly influence the concentration distribution in the human breathing area. In this case, if a contaminant generation amount is large, it can cause an adverse effect on human health, which means this must be taken into consideration. On the other hand, where the CRP1* variance is larger, the concentration of the contaminant generated from the materials cannot directly influence the concentration distribution in the human breathing area due to the indoor environment factors. Because of this, if a human working environment were created in a place where CRP1* variance was larger, the breathing quantity of toluene could be reduced locally in the same environment condition. Figure 3 and Table 2 show the CRP2.
Regardless of the condition and location of the human, the contaminant generated in the floor showed the largest effect on the human breathing area. Furthermore, in the case of Person C, the ratio of total breathing quantity, which was emitted from the left side walls, was more than two times larger than those of Persons A and B. This is because the movement of the contaminant generated from the right side walls was blocked by air inflow flowing around the wall side so that the contaminant could not influence the concentration of the contaminant near the human breathing area. On the other hand, in the case of the ceiling and floor, where the contaminant was generated nearly in the same areas, the contaminant that was 
emitted from the floor had a big influence on the breathing quantity of the contaminant.

\section{CONCLUSION}

In this study, a diffusion analysis was performed on the contaminants emitted from building materials in an indoor space using numerical CFD analysis. Furthermore, the effect of the diffusion concentration on indoor human breathing was quantitatively assessed using the CRP index. As a result, the following conclusions have been obtained.

If CRP1* is used, the concentration distribution at each area can be identified based on the concentration of the human breathing area. However, the CRP1* index is a relative value; therefore, the effect of indoor environment factors on contaminant concentration distribution in the indoor human breathing area can be assessed by identifying the variance of CRP1* around the human. Therefore, the effects of concentration reduction can be expected locally by placing a human working area in a place where the variance is large in the same conditions.

The effect of the contaminant emission amount in the sources in the indoor space on the contaminant total breathing quantity was assessed using CRP2. Increased indoor air quality improvement shall be required through the removal and dilution of the contaminant emission sources if the emission source with the CRP2 index of the human is higher.

\section{ACKNOWLEDGMENT}

This work was supported by the National Research Foundation of Korea (NRF) grant funded by the Korea government (MSIP) (No. 2008-0061908).

\section{REFERENCES}

[1] J. Seo, "Study on performance test and examination of absorptive building materials reducing indoor air pollutant using experiments and CFD analysis" Journal of the Architectural Institute of Korea, vol. 28, pp. 287-294, 2008.

[2] Y. Ataka, S. Kato, S. Murakami, Q. Zhu, K. Ito and T. Yokota, :'Study of effect of adsorptive building material on formaldehyde concentrations: Development of measuring methods and modeling of adsorption phenomena" Indoor Air, vol. 14, pp. 51-64, 2004.

[3] S. Kato, J. Yang, "Study on inhaled air quality in a personal airconditioning environment using new scales of ventilation efficiency", Building and Environment, vol. 43, pp. 494-507, 2008.

[4] T. Hayashi, Y. Ishizu, S. Kato and S. Murakami, "CFD analysis on characteristics of contaminated indoor air ventilation and its application in the evaluation of the effects of contaminant inhalation by a human occupant", Building and Environment, vol. 37, pp. 219-230, 2002.

[5] T. Hayashi, S. Kato and S. Murakami, "CFD analysis on contribution ratio of pollution source to breathing air quality in a stagnant room", Journal of Environmental Engineering, AIJ, vol. 603, pp. 41-45, 2006.

[6] X. Yang, "Study of building material emissions and indoor air quality", PhD Thesis, The Massachusetts Institute of Technology, 1999.

[7] T. Kim, Y. Lee and K. Han, "Contribution ratio of pollutant sources to concentration of room center", Proceedings of the AIK Spring Annual Conference, vol. 23, pp. 809-812, 2003.

[8] Joseph O. Hirschfelder, Charles F. Curtiss and R. Byron Bird, "Molecular theory of gases and liquids", Wiley-Interscience, 1964.

[9] The Society of Chemical Engineers, "Handbook of Chemistry", Tokyo, Japan, 1999.

[10] J. Seo, S. Kato, Y. Ataka and S. Nagao, "Measurement and CFD analysis on decreasing effect of toluene concentration with activated carbon and adsorptive building material", Proceedings of Healthy Building, vol. 5, pp. 101-106, 2006. 